\title{
Fetal HLA-G alleles and their effect on miscarriage
}

\author{
Altuğ Koç ${ }^{1, A-F}$, Özgür Kırbıyık ${ }^{1, B, D, E}$, Yaşar B. Kutbay ${ }^{1, B, D, E}$, Berk Özyllmaz ${ }^{1, B, D, E}$, \\ Taha R. Özdemir ${ }^{1, B, D, E}$, Özge Özer Kaya ${ }^{1, B-E}$, Gözde Kubat ${ }^{2, C}$, Zeynep Peker Koç, ${ }^{3, A, D}$ \\ ${ }^{1}$ Genetic Diagnosis Center, Tepecik Training and Research Hospital, Health Sciences University, Izmir, Turkey \\ ${ }^{2}$ Foreign Trade Department, Kazan Vocational School, Başkent University, Ankara, Turkey \\ ${ }^{3}$ Allergy and Immunology Clinic, Dr. Suat Seren Chest Diseases and Surgery Training and Research Hospital, Health Sciences University, Izmir, Turkey \\ A - research concept and design; $\mathrm{B}$ - collection and/or assembly of data; $\mathrm{C}$ - data analysis and interpretation; \\ $D$ - writing the article; $E$ - critical revision of the article; $F$ - final approval of the article
}

\section{Address for correspondence \\ Altuğ Koç}

E-mail:draltug@gmail.com

Funding sources

Financial contribution from Intron Saglik Company.

\section{Conflict of interest}

None declared

\section{Acknowledgements}

We would like to thank Intron Saglik Company for their kind financial contribution, ATQ Biotechnology Ltd. for their HLA-G typing and analysis support, and Dr. Ediz Yesilkaya for data analysis and interpretation.

Received on December 18, 2016 Reviewed on February 11, 2017 Accepted on March 22, 2017

\section{Abstract}

Background. Immunosuppression at the feto-maternal interface is crucial for a successful pregnancy outcome. Human leukocyte antigen- $G(H L A-G)$ seems to be a major contributor to fetal tolerance. The $H L A-G$ expression is seen in cytotrophoblasts and in maternal blood. Fetal $H L A-G$ acts on decidual antigen-presenting cells (APCS), natural killers (NKs) and T cells. Recent findings revealed that defects in placentation and their consequences are associated with maternal HLA-G variants and their expression levels.

Objectives. The objective of this article is to investigate the relationship between fetal HLA-G alleles and miscarriage, which has not been investigated to date.

Material and methods. The present study includes 204 recurrent miscarriage (RM) cases who were admitted to our clinic between 2012 and 2016. Twenty-eight miscarriage products without maternal cell contamination and any known pathology were analyzed by HLA-G typing. In addition, $3^{\prime}$ untranslated region (UTR) 14-base pair (bp) insertion/deletion polymorphism was also investigated by Sanger sequencing.

Results. For our population, the most frequent HLA-G type was $\mathrm{G}^{*} 01: 01$, both in the study group (30.3\%) and in the control group (47\%). The study revealed that the $\mathrm{G}^{*} 01: 04$ allele was significantly associated with miscarriage ( $p=0.007)$. The $3^{\prime}$ UTR 14bp deletion was more frequent in the miscarriage group, but there was no significant correlation.

Conclusions. HLA-G alleles seem to be related with miscarriage and should be considered in RM cases.

Key words: miscarriage, human leukocyte antigen- $G, G^{*} 01: 04,3^{\prime}$ untranslated region polymorphism

DOI

10.17219/acem/69692

Copyright

Copyright by Author(s)

This is an article distributed under the terms of the

Creative Commons Attribution Non-Commercial License

(http://creativecommons.org/licenses/by-nc-nd/4.0/) 


\section{Introduction}

Human leukocyte antigen-G (HLA-G) is an atypical HLA (Class Ib) molecule and is mainly expressed in immuneprivileged sites of the body. There are accumulating reports on the possible involvement of $H L A-G$ in cancer, transplantation, allergies, and autoimmune disorders. ${ }^{1-3}$ The role of $H L A-G$ in the maintenance of maternal tolerance and in reproduction has been also widely studied. ${ }^{4}$ Up to $50 \%$ of the endometrium of a pregnant uterus (decidua) is composed of maternal immune cells. ${ }^{5}$ The mother is expected to generate graft-attacking antibodies and a cytotoxic $\mathrm{T}$ lymphocyte response to foreign paternal HLA or other antigens expressed by the fetal cells. ${ }^{1}$ Ensuring immune tolerance to the semi-allogenic fetus is achieved by the immune modulation of decidual natural killer (NK) cells, antigen presenting cells (APCs), including dendritic cells and macrophages (innate immune system), and by regulatory $\mathrm{T}$ cells (adaptive immune system). Shallow fetal trophoblast invasion is likely related to a partial breakdown of maternal-fetal immune tolerance and may underlie recurrent miscarriage (RM) and preeclampsia.,

Trophoblasts strictly regulate their expression of HLA genes. HLA Class Ia (A, B and C) are not expressed by trophoblasts to prevent a maternal immune response - the exception is the mild expression of $H L A-C$. A special set of HLA Class (Ib: E, F and G) is presented on the fetal cells, which are thought to have an inhibitory effect on the maternal immune system. ${ }^{1}$ These molecules share structural similarities with Class Ia antigens, but also have some distinct features. In contrast to Ia antigens, Class Ib antigens are not ubiquitous. Their expressions are organ-specific and conditional. Atypical Class Ib antigens have a low number of alleles and have both soluble and membrane-bound forms. On the other hand, typical Class Ia antigens are highly polymorphic and only have membrane-bound forms. ${ }^{7}$

The expression of $H L A-G$ was first described in the placenta as the conventional $\beta 2 m$-linked, membrane-bound form. However, studies reveal that $H L A-G$ has 7 splice variants, including 4 membrane-bound (HLA-G1 to - G4) and 3 soluble isoforms (HLA-G5 to -G7). Furthermore, membrane-bound $H L A-G 1$ can be shed and released as soluble $H L A-G 1$. About 50 HLA-G alleles and 16 proteins have been reported to date. ${ }^{8}$

$H L A-G$ has 7 introns and 8 exons. Exon 1 is related to a signal peptide. Exons 2, 3 and 4 encode the extracellular domains: $\alpha 1, \alpha 2$ and $\alpha 3$, respectively. Intron 4 contains a stop sequence and yields soluble $G 5$ and $G 6$ isoforms. The transmembrane domain is encoded by exon 5 . Exons 6 and 7 encode the intracellular domain.

The polymorphisms of $H L A-G$ have also been widely studied. ${ }^{1,4,8-12}$ The $H L A-G$ gene has 14-base pair (bp) insertion/deletion (ins/del) polymorphism in 3' untranslated region (UTR), which influences messenger RNA (mRNA) size and stability. ${ }^{1}$ An inserted $14 \mathrm{bp}$ sequence probably acts as a cryptic splice site and causes a 92bp deletion in 3' UTR. As a result, $H L A-G$ mRNA stability is increased., ${ }^{1,8}$

Recent studies have focused on the functions of $H L A-G$ isoforms, ${ }^{3} H L A-G$ dimers and $\beta 2$-microglobulin ( $\left.\beta 2 \mathrm{~m}\right)$ association. ${ }^{13,14}$ The disulfide-linked homodimer of $\beta 2 \mathrm{~m}$-associated $H L A-G$ is found to be the major fraction expressed by trophoblast cells. ${ }^{15}$ LIRB1 has been proposed as the principal ligand for the $H L A-G$ dimer, which is expressed on decidual APCs, NKs and T lymphocytes. Interactions with LIRB2, CD160, KIR2DL4, and other receptors have also been reported. ${ }^{15-17}$

$H L A-G$ alleles have been investigated in women with a history of miscarriage and in their partners, but not in conceptus material to date. One of the reasons for that is the difficulty in obtaining maternal-cell-free fetal tissues and the increased failure rates for cell culture and polymerase chain reaction (PCR). In addition to these factors, many of the miscarriage samples contain chromosomal anomalies which should be excluded from the study groups. The determination of parental HLA-G alleles, as in the current literature, just leads to indirect estimations about the fetal HLA-G status. Definite fetal HLA-G genotyping should be the preferred approach instead of parental genotyping, because $H L A-G$ is expressed by fetal trophoblasts. ${ }^{15}$ In this study, we aimed to find an association between fetal HLA-G type, HLA-G 3' UTR 14bp ins/del polymorphism and miscarriage, and to determine the most common $H L A-G$ alleles in our population. ${ }^{18}$

\section{Material and methods}

\section{Study and control groups}

The study group consisted of 28 cases out of 204 patients referred to our center between 2012 and 2016 who had at least 2 miscarriages (range: $2-4$ ). All of the mothers were investigated for hereditary thrombophilia. Miscarriage samples were karyotyped and analyzed by quantitative fluorescent polymerase chain reaction (QF-PCR) for aneuploidies of chromosomes 13, 15, 16, 18, 21, and 22, and sex chromosomes. The short tandem repeat (STR) markers of a QF-PCR kit were also used to detect maternal cell contamination. At least 10 informative STR markers were needed to exclude maternal cell contamination. The samples with 46,XY karyotype or 46,XX karyotype with no maternal contamination were included. Miscarriage materials with chromosomal anomalies, culture failure or PCR failure were excluded. The mothers with thrombophilic mutations, a history of in vitro fertilization (IVF) or any known obstetric reason for miscarriage, such as uterine malformations, antiphospholipid syndrome or hormone disorders, were also excluded. Fetuses with anencephaly, increased nuchal translucency, anhydramnios, early rupture of membranes, or other major malformations on fetal ultrasonography were excluded. The mean age 
of mothers was 30.3 years and the majority of pregnancy losses occurred during the $1^{\text {st }}$ trimester (gestational weeks 5-15). Twenty-one healthy individuals representing successful deliveries were used as controls for HLA-G types determined by the sequencing of exons 2, 3 and 4 . For 3' UTR polymorphism, 101 healthy individuals were used as controls. The project received the permission of the local Tepecik Training and Research Hospital ethics committee.

\section{Routine genetic workup of miscarriage}

The routine genetic investigation of miscarriage cases included a conventional cytogenetic analysis of the miscarriage sample by GTG banding (550 bands) and a QF-PCR analysis with 26 STR markers (Compact v3 QF-PCR; Devyser, Stockholm, Sweden). Hereditary thrombophilia mutations (Factor V Leiden and Factor II G20210A) were investigated by real-time PCR (FV R2 [H1299R] QLP 3.0; Prothrombin QLP 3.0, Iontek, Istanbul, Turkey) from maternal blood.

\section{HLA-G typing}

Exons 2, 3 and 4 were sequenced for $H L A-G$ typing. Commercial primer/oligonucleotide sets dedicated for high-resolution HLA sequencing-based typing (SBT) for the identification of HLA alleles were used according to the manufacturer's protocols (SBTexcellerator ${ }^{\circledR}$ HLA Kits; GenDx, Utrecht, the Netherlands).

\section{HLA-G 3' UTR 14bp ins/del polymorphism (rs371194629)}

The polymorphism was investigated by Sanger sequencing. The PCR primers were F: 5'-TGT GAA ACA GCT GCC CTG TGT-3' and R: 5'-GTC TTC CAT TTA TTT TGT-3'. The PCR conditions were as follows: the first denaturation was at $95^{\circ} \mathrm{C}$ for $10 \mathrm{~min} ; 35$ cycles of denaturation at $95^{\circ} \mathrm{C}$ for $30 \mathrm{~s}$, annealing at $60^{\circ} \mathrm{C}$ for $45 \mathrm{~s}$, and elongation at $72^{\circ} \mathrm{C}$ for $45 \mathrm{~s}$; and the last elongation was at $72^{\circ} \mathrm{C}$ for $7 \mathrm{~min}$. The PCR products were purified as follows: $5 \mu \mathrm{L}$ of PCR products were treated with $2 \mu \mathrm{L}$ of ExoSAP-IT enzyme (USB; Affymetrix, Santa Clara, USA) at $37^{\circ} \mathrm{C}$ for $30 \mathrm{~min}$ and at $85^{\circ} \mathrm{C}$ for $15 \mathrm{~min}$. Sequence PCR (cycle sequencing) was done using a reverse PCR primer $(5 \mathrm{pmol})$ and a BigDye ${ }^{\circledR}$ Terminator v. 3.1 Cycle Sequencing Kit (Lifetechnologies, Waltham, USA). The sequence PCR conditions were as follows: at $96^{\circ} \mathrm{C}$ for $10 \mathrm{~s}$, at $50^{\circ} \mathrm{C}$ for $5 \mathrm{~s}$ and at $60^{\circ} \mathrm{C}$ for $4 \mathrm{~min}$; the cycle was repeated 25 times. The products of sequence PCR were purified (the $2^{\text {nd }}$ purification) by spin colon (ZR DNA Sequencing Clean-up Kit ${ }^{\mathrm{TM}}$, Zymo Research, Irvine, USA). Sanger sequencing was performed by capillary electrophoresis after 5 min of denaturation (3500 Genetic Analyzer; Lifetechnologies). The obtained sequences were analyzed using SeqScape ${ }^{\circledR}$ software v. 3.0 (Applied Biosystems by Life Technologies, Carlsbad, USA).

\section{Statistical analysis}

Allelic and genotypic frequencies were determined from the observed genotype counts, and the expectations of the Hardy-Weinberg equilibrium were evaluated by $x^{2}$ analysis. The $\chi^{2}$ test was used for comparisons between allelic and genotypic frequencies. Statistical analysis was done using SPSS v. 13 statistical software (SPSS Inc., Chicago, USA). A p-value $<0.05$ was considered statistically significant.

\section{Results}

In all groups, there were $10 H L A-G$ types, coded for 4 distinct proteins, and their combinations gave rise to 8 distinct genotypes. The most frequent $H L A-G$ type was $G^{*} 01: 01$ both in the study group (30.3\%) and in the control group (47\%). The findings are summarized in Table 1. $\mathrm{G}^{*} 01: 01 / * 01: 01$ was the most frequent genotype for the

Table 1. Comparison of study and control groups' HLA-G types

\begin{tabular}{|l|c|c|c|}
\hline HLA-G types* & $\begin{array}{c}\text { Frequencies } \\
\text { in miscarriage } \\
\text { samples, \% (n) }\end{array}$ & $\begin{array}{c}\text { Frequencies } \\
\text { in control } \\
\text { samples, \% (n) }\end{array}$ & p-value \\
\hline $01: 01$ & $30.3(17 / 56)$ & $47(19 / 42)$ & \\
\hline $01: 01: 01$ & $12.5(7 / 56)$ & $17.5(7 / 42)$ & \\
\hline $01: 01: 02$ & $7.1(4 / 56)$ & $5(2 / 42)$ & 0.189 \\
\hline $01: 01: 03$ & $3.5(2 / 56)$ & $2.5(1 / 42)$ & \\
\hline $01: 01: 12$ & $1.7(1 / 56)$ & - & 0.176 \\
\hline $01: 06$ & $7.15(4 / 56)$ & $22.5(9 / 42)$ & 0.299 \\
\hline $01: 03$ & $7.15(4 / 56)$ & $5(2 / 42)$ & \\
\hline $01: 04: 01$ & $12.5(7 / 56)$ & $5(2 / 42)$ & $0.007^{* *}$ \\
$01: 04: 04$ & $12.5(7 / 56)$ & - & \\
\hline $01: 04$ & $5.3(3 / 56)$ & - & \\
\hline
\end{tabular}

The study group consisted of 28 miscarriage samples (56 alleles) and the control group included 21 blood samples (42 alleles) from healthy individuals. There were 10 HLA-G types that code 4 proteins. * The HLA-G types with the same initial 2 digits have the same amino acid (aa) sequence, e.g., 01:04:01 and 01:04:04 code for the same specific protein; ** statistically significant.

For HLA nomenclature, see http://hla.alleles.org/nomenclature/naming.html.

study and control groups: its frequency was $35.7 \%$ in the study group and $48 \%$ among the controls. The genotypes G*01:04/*01:04, G*01:03/*01:04 and G*01:03/*01:06 were found only in the study group, and the $G^{*} 01: 06 /{ }^{*} 01: 06$ genotype was found only in the control group (Table 2). There was a significant association between the $H L A-G$ allele $\mathrm{G}^{*}$ 01:04 and miscarriage $(\mathrm{p}=0.007)$.

The results of 3' UTR polymorphism are presented in Table 3. The frequency distribution of alleles was in Hardy-Weinberg equilibrium. In the miscarriage samples, the most frequent allele was the 14bp deletion (57\%) and the most frequent genotype was homozygous deletion (39\%). Homozygous deletion was approx. 2 times more frequent 
in the miscarriage group than in the controls. In the control group, the most frequent allele was the allele with insertion (54\%), and heterozygosity was the most frequent genotype (53\%).

Table 2. Comparison of HLA-G genotype frequencies in study and control groups

\begin{tabular}{|c|c|c|c|}
$\begin{array}{c}\text { HLA-G } \\
\text { genotypes** }\end{array}$ & $\begin{array}{c}\text { Frequencies } \\
\text { in miscarriage } \\
\text { samples, \% (n) }\end{array}$ & $\begin{array}{c}\text { Frequencies } \\
\text { in control } \\
\text { samples, \% (n) }\end{array}$ & p-value \\
\hline$* 01: 01 /{ }^{*} 01: 01$ & $35.7(10 / 28)$ & $48(10 / 21)$ & \\
\hline$* 01: 01 /{ }^{*} 01: 04$ & $25(7 / 28)$ & $9.5(2 / 21)$ & \\
\hline$* 01: 04 /{ }^{*} 01: 04$ & $14.3(4 / 28)$ & - & 0.128 \\
\hline$* 01: 01 /{ }^{*} 01: 06$ & $10.7(3 / 28)$ & $23.5(5 / 21)$ & \\
\hline$* 01: 03 /{ }^{*} 01: 04$ & $7.1(2 / 28)$ & - & \\
\hline$* 01: 01 /{ }^{*} 01: 03$ & $3.6(1 / 28)$ & $9.5(2 / 21)$ & \\
\hline$* 01: 03 /{ }^{*} 01: 06$ & $3.6(1 / 28)$ & - & \\
\hline$* 01: 06 /{ }^{*} 01: 06$ & - & $9.5(2 / 21)$ & \\
\hline
\end{tabular}

The study group consisted of 28 miscarriage samples and the control group included 21 blood samples from healthy individuals. There were 8 HLA-G genotypes. * The same genotype name was used for genotypes specific to the same protein, e.g., $\mathrm{G}^{*} 01: 04: 01 /{ }^{*} 01: 04: 04$ was shown as *01:04/*01:04

Table 3. Frequency distribution of the $3^{\prime}$ UTR 14bp ins/del polymorphism (rs371194629) in miscarriage and control samples

\begin{tabular}{|c|c|c|c|}
\hline Alleles & $\begin{array}{l}\text { Frequencies } \\
\text { in miscarriage } \\
\text { samples, \% (n) }\end{array}$ & $\begin{array}{l}\text { Frequencies } \\
\text { in control } \\
\text { samples, \% (n) }\end{array}$ & $p$-value \\
\hline Insertion & $43(24 / 56)$ & $54(108 / 202)$ & 0.301 \\
\hline Deletion & $57(32 / 56)$ & $46(94 / 202)$ & 0.082 \\
\hline \multicolumn{4}{|c|}{ Genotypes } \\
\hline Heterozygous & $36(10 / 28)$ & $53(54 / 101)$ & \multirow{3}{*}{0.215} \\
\hline $\begin{array}{l}\text { Homozygous } \\
\text { insertion }\end{array}$ & $25(7 / 28)$ & $27(27 / 101)$ & \\
\hline $\begin{array}{l}\text { Homozygous } \\
\text { deletion }\end{array}$ & $39(11 / 28)$ & $20(20 / 101)$ & \\
\hline
\end{tabular}

The study group consisted of 28 miscarriage samples (56 alleles) and the control group included 101 blood samples (202 alleles) from healthy adults.

\section{Discussion}

The $\beta 2 \mathrm{~m}$-associated/free $H L A-G$ dimers are shown to be expressed from trophoblasts. ${ }^{13,14}$ HLA-G stimulates trophoblastic invasion. ${ }^{3}$ In addition to this, it is one of the major tolerogenic molecules in pregnancy. ${ }^{1,2}$ The $H L A-G$ expression is studied in preeclampsia, recurrent miscarriage and IVF. ${ }^{8}$ The results indicated an association between an $H L A-G$ expression pattern and a risk of RM as well as other disorders. ${ }^{7}$

We proposed that the fetal $H L A-G$ alleles may underlie miscarriage and that the condition may recur, so we could find the miscarriage-prone $H L A-G$ alleles in the conceptus material of mothers with a history of miscarriage. Healthy adults were used as controls and they were assumed not to carry miscarriage-prone alleles. We investigated samples of 204 miscarriage cases that had at least 1 previous miscarriage. Triploidy (9 cases), trisomy 15 (8 cases), trisomy 16 ( 6 cases), and 45, X (5 cases) were the leading causes of miscarriage in our series, and all cases with genetic pathology were excluded from the study. Twenty-eight out of 204 samples from distinct mothers constituted our study group.

There were $10 H L A-G$ types coded for 4 specific proteins (Table 1) and 8 genotypes were determined in all groups (Table 2). The $\mathrm{G}^{*} 01: 04$ allele was found in a homozygous state in 4 cases of the study group (14.3\%) and in none of the controls. There was a significant correlation between the fetal HLA-G allele $\mathrm{G}$ *01:04 and miscarriage ( $\mathrm{p}=0.007)$. As an interesting point, all the samples with the $G^{*} 01: 04$ allele also had the 14bp deletion allele. The $\mathrm{G}^{*} 01: 04$ allele may be linked with the $14 \mathrm{bp}$ deletion and had to be investigated in our population.

Ober et al. showed that a variation in the parental $H L A-G$ promoter influences miscarriage rates. They hypothesized that the transmission of a high-risk allele from either parent to the fetus would be associated with fetal loss. ${ }^{10} \mathrm{Ma}$ ternal homozygosity for $14 \mathrm{bp}$ insertion polymorphism has been proposed to predispose to miscarriage. ${ }^{11} \mathrm{We}$ found that the allele with the 3' UTR 14bp deletion polymorphism was the most frequent allele in the study group (57\%). The homozygous genotype of the same allele was about 2 times more common in the study group than in the controls (39\% vs $20 \%)$. The $H L A-G$ allele with insertion was the most frequent (54\%) in the control group (Table 3). The 14bp deletion of 3' UTR seems to be related with miscarriage, but the restricted number of study group subjects $(\mathrm{n}=28)$ unfortunately prevented any statistical association to be revealed.

In conclusion, fetal G*01:04 HLA-G type and the 3' UTR $14 \mathrm{bp}$ deletion polymorphism may underlie miscarriages, and investigations of $H L A-G$ alleles with a larger sample of miscarriage products and related immune components (such as LIRB1 and NKs) may contribute to a better understanding of the miscarriage process.

\section{References}

1. Hunt JS, Petroff MG, McIntire RH, Ober C. HLA-G and immune tolerance in pregnancy. FASEB J. 2005;19:681-693.

2. Favier $B$, HoWangYin $K-Y, W u$, et al. Tolerogenic function of dimeric forms of HLA-G recombinant proteins: A comparative study in vivo. PLoS One 6(7): e21011. https://doi.org/10.1371/journal.pone.0021011

3. Guo $\mathrm{Y}$, Lee $\mathrm{CL}$, So $\mathrm{KH}$, et al. Soluble human leukocyte antigen-g5 activates extracellular signal-regulated protein kinase signaling and stimulates trophoblast invasion. PLoS One. 2013;8(10):e76023. doi: 10.1371/journal.pone.0076023

4. Larsen $M H$, Bzorek M, Pass MB, et al. Human leukocyte antigen-G in the male reproductive system and in seminal plasma. Mol Hum Reprod. 2011;17(12):727-738.

5. Hsu P, Nanan RKH. Innate and adaptive immune interactions at the fetal-maternal interface in healthy human pregnancy and preeclampsia. Front Immunol. 2014;28:125. 
6. Zhao L, Purandare B, Zhang J, Hantash BM. $32-$ Microglobulin-free HLA-G activates natural killer cells by increasing cytotoxicity and proinflammatory cytokine production. Hum Immunol. 2013;74:417-424.

7. Mosaferi E, Majidi J, Mohammadian M. HLA-G expression pattern: Reliable assessment for pregnancy outcome prediction. Adv Pharm Bull. 2013;3:443-446.

8. Dahl M, Djurisic S, Hviid TV. The many faces of human leukocyte antigen-G: Relevance to the fate of pregnancy. J Immunol Res. 2014; 591489. doi: 10.1155/2014/591489

9. Warner CM, Tyas DA, Goldstein C, Comiskev M, Cohen J, Brenner CA Genotyping: The HLA system and embryo development. Reprod Biomed Online. 2002;4:133-139.

10. Ober C, Aldrich CL, Chervoneva I, et al. Variation in the HLA-G promoter region influences miscarriage rates. Am J Hum Genet. 2003;72: 1425-1435.

11. Christiansen $O B$, Kolte $A M$, Dahl M, et al. Maternal homozygocity for a 14 base pair insertion in 3' UTR of the HLA-G gene and carriage of HLA class II alleles restricting HY immunity predispose to unexplained secondary recurrent miscarriage and low birth weight in children born to these patients. Hum Immunol. 2012;73:699-705
12. Jassem RM, Shani WS, Loisel DA, Sharief M, Billstrand C, Ober C. HLA-G polymorphisms and soluble HLA-G protein levels in women with recurrent pregnancy loss from Basrah province in Iraq. Hum Immunol. 2012;73:811-817.

13. Apps R, Gardner L, Sharkey AM, Holmes N, Moffett A. A homodimeric complex of HLA-G on normal trophoblast cells modulates antigenpresenting cells via LILRB1. Eur J Immunol. 2007;37:1924-1937.

14. Morales PJ, Pace JL, Platt JS, Langat DK, Hunt JS. Synthesis of beta (2)-microglobulin-free, disulphide-linked HLA-G5 homodimers in human placental villous cytotrophoblast cells. Immunology. 2007; 122:179-188.

15. Kuroki K, Maenaka K. Immune modulation of HLA-G dimer in maternal-fetal interface. Eur J Immunol. 2007;37:1727-1729.

16. Clements CS, Kjer-Nielsen L, Kostenko L, et al. Crystal structure of HLA-G: A nonclassical MHC class I molecule expressed at the fetalmaternal interface. Proc Natl Acad Sci. 2005;102:3360-3365.

17. Yan WH, Fan LA. Residues Met76 and GIn79 in HLA-G alpha1 domain involve in KIR2DL4 recognition. Cell Res. 2005;15:176-182.

18. Kuroshli Z, Gourabi H, Bazrgar M, Sanati MH, Bahraminejad E, Anisi K. $H L A-G$ allele and haplotype frequencies in a healthy population of Iran. Iran J Allergy Asthma Immunol. 2014;13:207-213. 